\title{
Analisa Arc Flash pada Sistem Kelistrikan Di PT. Asahimas Flat Glass Tbk. Sidoarjo
}

\author{
Moch. Irsad Taufiqi, Margo Pujiantara, Sjamsjul Anam \\ Jurusan Teknik Elektro, Fakultas Teknologi Industri, Institut Teknologi Sepuluh \\ Nopember (ITS) Jl. Arief Rahman Hakim, Surabaya 60111 \\ E-mail: fiqifrancesc@gmail.com; margo@ee.its.ac.id; anam@ee.its.ac.id
}

\begin{abstract}
Abstrak - Arc Flash adalah total energi yang dilepaskan ketika terjadi gangguan hubung singkat. Energi akan dilepaskan melalui udara mengalir ke fasa lain, netral atau mengalir ke tanah. Ketika pekerja yang tidak dilengkapi alat pelindung diri berada di dekat dengan Arc Flash, maka akan menyebabkan cedera serius dan bahkan kematian. Berdasarkan standar IEEE 1584-2002 yang mengatur tentang analisa bahaya busur api pada sistem tegangan rendah dan menengah, pengguna dapat dengan mudah menentukan batas keamanan untuk para pekerja. Menurut rekomendasi standar IEEE perhitungan arus hubung singkat selalu memperhatikan kontribusi arus gangguan dari generator, motor induksi dan sinkron. Besar kecilnya energi arc flash dapat ditentukan dari beberapa sudut pandang. Diantaranya ialah nilai energi arc flash akan besar apabila dihitung dengan menggunakan arus bolted three phase fault, sedangkan dari sudut arc clearing time yang didapat dari waktu dimana arus gangguan saat itu terjadi akan menghasilkan nilai energi busur api yang lebih rendah. Untuk mengurangi atau menurunkan nilai dari arc clearing time ini banyak metode yang digunakan, diantaranya adalah melakukan resetting koordinasi proteksinya seperti yang dilakukan dalam tugas akhir ini. Untuk hasil yang didapat pada tugas akhir ini adalah pada tipikal 1 nilai insiden energi tertinggi $31.576 \mathrm{cal} / \mathrm{cm}^{2}$ turun menjadi $10.764 \mathrm{cal} / \mathrm{cm}^{2}$, pada tipikal 2 nilai insiden energi tertinggi $30.387 \mathrm{cal} / \mathrm{cm}^{2}$ turun menjadi $16.8 \mathrm{cal} / \mathrm{cm}^{2}$, pada tipikal 3 nilai insiden energi nya mengalami penurunan yaitu dari $30.513 \mathrm{cal} / \mathrm{cm}^{2}$ menjadi $15.94 \mathrm{cal} / \mathrm{cm}^{2}$.
\end{abstract}

Kata Kunci-Arc Flash, Arc clearing time, Arus bolted three phase fault, koordinasi proteksi, standar IEEE 15842002.

\section{PENDAHULUAN}

PT. Asahimas Flat Glass Tbk. Sidoarjo adalah perusahaan produksi kaca lembaran dan kaca pengaman otomotif. Untuk mejaga kestabilan produksi maka diperlukan sistem kelistrikan yang handal. Sistem kelistrikan yang handal adalah sistem kelistrikan yang dapat menyalurkan daya dari sumber daya ke beban dengan baik. Sistem kelistrikan yang baik harus dilengkapi dengan sistem proteksi yang baik pula.

Sistem proteksi berkaitan dengan arus gangguan. PT. Asahimas Flat Glass Tbk. Sidoarjo merupakan salah satu perusahaan yang besar dengan sistem kelistrikan yang besar pula. Semakin besar kapasitas sumber listrik yang digunakan untuk operasi produksi, maka semakin besar pula nilai arus gangguan dan bahaya busur api (arc flash).

Standar NFPA 70E-2004 menetapkan fenomena arc flash sebagai kondisi yang berbahaya yang berhubungan dengan pelepasan energi yang disebabkan busur api. Energi akan dilepaskan melalui udara mengalir ke fasa yang lain, netral atau mengalir ke tanah. Arc flash merupakan fenomena percikan api yang timbul akibat adanya arus gangguan hubung singkat.

Hal-hal yang dapat memicu gangguan hubung singkat dapat disebabkan berbagai faktor, salah satunya adalah akibat kegagalan isolasi pada konduktor atau rel busbar pada switchgear sehingga memicu terjadinya perpindahan muatan yang diakibatkan perbedaan potensial. Semakin cepat rele pengaman bekerja semakin kecil pula busur api yang dihasilkan dan berlaku sebaliknya. Oleh karena itu, studi untuk mengetahui besar busur api yang diasilkan pada masingmasing switchgear perlu dilakukan untuk memberikan peringatan kepada para pekerja maupun orang disekitarnya akan dampak yang ditimbulkan serta perlengkapan keselamatan yang harus dikenakan sebagai langkah pencegahan agar terhindar insiden bahaya percikan busur api. PT. Asahimas Flat Glass, Tbk. perlu melakukan perhitungan insiden energi arc flash karena pada studi-studi sebelumnya belum ada yang menganalisa tentang bahaya arc flash dan pengklarifikasian katagori besar energi arc flash sesuai dengan katagorinya.

Pada tugas akhir ini standar yang digunakan sebagai acuan dalam katagori bahaya arc flash yang ditimbulkan adalah standar NEC [1]. Namun, pada standar tersebut masih memiliki kekurangan dalam penentuan energi arc flash yang timbul. Maka penulis paper ini akan memodifikasi standart NEC untuk menentukan pengkatagorian dan penentuan PPE untuk kelengkapan pengamanan pada lokasi terjadinya insiden arc flash. Pada beberapa kasus tidak dicantumkan tanda bahaya arc flash pada peralatan dan hal tersebut sangat berbahaya jika terjadi insiden arc flash. Tanda arc flash pada peralatan sangat penting untuk memberikan peringatan pada manusia untuk berhati-hati dan menggunakan perlengkapan pengaman jika ada kegiatan disekitar peralatan tersebut. Untuk menentukan perlengkapan pengaman manusia dapat dilihat pada NFPA70E [3].

Selain berdampak pada manusia, arc flash juga berdampak pada peralatan-peralatan lain disekitarnya. Besar arc flash tergantung dari waktu kerja sistem pengaman akibat gangguan arus hubung singkat [4]. Oleh Karena itu, studi untuk mengetahui besar arc flash perlu dilakukan untuk memberikan 
peringatan kepada para perkerja maupun orang-orang disekitarnya terhadap dampak yang timbul serta perlengkapan keselamatan yang harus dikenakan sebagai langkah awal pencegahan dari bahaya arc flash [5].

\section{URAIAN MATERI}

\section{A. Busur Api Listrik (Arc-flash)}

Arc flash adalah hasil dari suatu pelepasan energi yang cepat yang disebabkan karena arcing fault diantara satu bus bar dengan bus bar lainnya, netral atau ground. Arcing fault sendiri dapat didefiniskan sebagai busur api yang diakibatkan oleh arus gangguan. Selama terjadi arc fault udara adalah sebagai konduktor. Arc fault umumnya dibatasi pada sistem dimana tegangan bus lebih dari 120 Volt. Level tegangan yang lebih rendah biasanya tidak akan mengalami suatu arc. Besar arcing fault current biasanya lebih rendah dari besar arus bolted fault dan di bawah rating circuit breaker [1].

Plasma energi yang dihasilkan dapat menimbulkan beberapa efek fisik antara lain berupa ledakan bola api yang terhempas ke luar, panas yang dihasilkan dapat menyebabkan luka bakar yang parah, cahaya yang menyilaukan, gelombang bertekanan yang dihasilkan seolah-olah seperti martil menghantam bagian dada dari tubuh hingga dapat menghempaskan orang disekitarnya, suara ledakan yang dapat mengganggu pendengaran dan tetesan logam cair akibat konduktor yang meleleh berterbangan ke segala arah seperti pecahan peluru. Bolted-fault current dapat disebabkan beberapa faktor diantaranya kegagalan mekanik, kegagalan isolasi, debu dan korosi atau kesalahan pekerja yang bekerja pada peralatan bertegangan [2].

\section{B. Perhitungan Energi Arc-Flash Berdasarkan Standar IEEE 1584-2002 [3]}

Arcing fault current $\left(\mathrm{I}_{\mathrm{a}}\right)$ :

$\lg \mathrm{I}_{\mathrm{a}}=0,00402+0,983 \lg \mathrm{Ibf}$

dimana,

$\lg =\log 10$

$\mathrm{I}_{\mathrm{a}}=$ arus busur api / arcing current $(\mathrm{kA})$

$\mathrm{Ibf}=$ bolted three-phase fault at the bus symetrical rms (kA)

Dari persamaan (1) dapat ditulis kembali dengan persamaan sebagai berikut,

$$
\begin{array}{ll}
\lg \mathrm{I}_{\mathrm{a}}-0,983 \lg \mathrm{Ibf}_{b} & =0,00402 \\
\lg \mathrm{I}_{\mathrm{a}}-\lg \mathrm{Ibf}_{b} 0,983 & =0,00402 \\
\lg \left(\mathrm{I}_{\mathrm{a}} / \mathrm{Ibf} 0,983\right) & =0,00402 \\
\mathrm{I}_{\mathrm{a}} / \mathrm{I}_{b f} 0,983 & =100,00402 \\
\mathrm{I}_{\mathrm{a}} / \mathrm{I}_{b f} 0,983 & =1,00929 \\
\mathrm{I}_{\mathrm{a}} & =1,01 \times \mathrm{I}_{b f} 0,983
\end{array}
$$

Energi arc-flash $\left({ }^{\mathrm{Joule}} / \mathrm{cm}^{2}\right)$ :

$$
\lg \mathrm{En}=\mathrm{K}_{1}+\mathrm{K}_{2}+1,081 \lg \mathrm{I}_{\mathrm{a}}+0,0011 \mathrm{G}
$$

atau bisa dituliskan dengan persamaan berikut,

$$
\mathrm{En}=\mathrm{I}_{\mathrm{a}}{ }^{1,081} \times 10^{(\mathrm{K} 1+\mathrm{K} 2+0,0011 \mathrm{G})}
$$

(3)

Dengan adanya variabel waktu, $\mathrm{x}$ faktor dan jarak antara peralatan dengan pekerja maka akan menghasilkan jumlah energi yang dilepaskan ke udara. Besarnya dapat dituliskan dalam persamaan berikut dalam satuan $\mathrm{cal}_{/ \mathrm{cm}}{ }^{2}$.

$$
\mathrm{E}=\mathrm{C}_{\mathrm{f}} \times \operatorname{En} \times(\mathrm{t} / 0,2)(610 / \mathrm{D})^{\mathrm{X}}
$$

Substitusi En dari persamaan (3) ke (4),

$$
\begin{aligned}
E= & C_{f} \times\left(I_{a}{ }^{1,081} \times 10^{(K 1+K 2+0,0011 G)}\right) \times \\
& (t / 0,2) \times(610 / D)^{X} \\
= & C_{f} \times 10^{(K 1+K 2+0,0011 G)}(610 / D)^{X} \times I_{a} \begin{array}{r}
1,081 \\
(t / 0,2)
\end{array}
\end{aligned}
$$

Dimana,

En $=$ Insiden energi normal tanpa pengaruh waktu dan jarak $\left(\right.$ Joule $/ \mathrm{cm}^{2}$ ).

$\mathrm{K}_{1}=-0,792$ untuk konfigurasi terbuka dan $-0,555$ untuk kofigurasi tertutup atau box.

$\mathrm{K}_{2}=0$ untuk sistem ungrounded or high-resistance dan -0,113 untuk sistem grounded.

$\mathrm{G} \quad=$ gap antara konduktor $(\mathrm{mm})$

$\mathrm{E} \quad=$ Insiden energi $\left(\mathrm{cal}_{/} \mathrm{cm}^{2}\right)$

$\mathrm{C}_{\mathrm{f}}=1,0$ untuk tegangan lebih dari $1 \mathrm{kV}$ dan 1,5 untuk tegangan kurang dari $1 \mathrm{kV}$

$\mathrm{t}=$ arcing time $(\mathrm{sec})$ pada alat proteksi di atas bus

$\mathrm{D}=$ jarak batas pekerja dari sumber $\operatorname{arcing}(\mathrm{mm})$

$\mathrm{x} \quad=$ eksponen jarak

I $\mathrm{bf}_{\mathrm{bf}} \quad$ bolted three-phase fault at the bus symetrical rms (kA)

Berdasarkan standart NFPA-70E - May 2003 ROP dalam

Annex B method [4], maka :

Mencari besar incident energy arc flash

$\mathrm{E}=793 \mathrm{x} \mathrm{D}^{-2} \mathrm{x}$ V x Ibf $\mathrm{xt}$

Dimana,

$\mathrm{E}=$ insiden energy $\left(\mathrm{cal} / \mathrm{cm}^{2}\right)$

$\mathrm{D}=$ working distance (inch)

$\mathrm{V}=$ tegangan $(\mathrm{kV})$

Ibf $=$ bolted fault current $(\mathrm{kA})$

$\mathrm{t}=$ arcing time (second)

\section{Pengelompokkan Kategori Energi Busur Api dengan} Perlengkapan Keselamatan Diri Sesuai Standar NFPA 70E-2003

Setelah dilakuan perhitungan energi busur api yang dihasilkan pada tiap-tiap bus switchgear. Langkah selanjutnya adalah mengkategorikan perlengkapan keselamatan yang harus digunakan bagi siapa saja yang masuk ke area tersebut (workers). Kategori ini didasari atas besarnya energi yang dihasilkan serta dampak yang ditimbulkan bagi tubuh manusia. Pemilihan perlengkapan perlindungan diri yang tepat memberikan kenyamanan para pekerja agar dapat bekerja 
dengan efektif. Pengelompokkan kategori dapat dilihat pada Tabel 1.

Tabel 1.

Kategori Perlengkapan Pelindung Diri

(Personal Protective Equipment/PPE) [5]

\begin{tabular}{|c|c|l|}
\hline Category & Cal/ $\mathrm{cm}^{2}$ & \multicolumn{1}{|c|}{ Clothing } \\
\hline 0 & 1,2 & Unterated Cotton \\
\hline 1 & 4 & $\begin{array}{l}\text { Flame retardant (FR) shirt and FR } \\
\text { pants }\end{array}$ \\
\hline 2 & 8 & $\begin{array}{l}\text { Cotton underwear FR shirt and FR } \\
\text { pants }\end{array}$ \\
\hline 3 & 25 & $\begin{array}{l}\text { Cotton underwear FR shirt, FR pants } \\
\text { and FR coveralls }\end{array}$ \\
\hline 4 & 40 & $\begin{array}{l}\text { Cotton underwear FR shirt, FR pants } \\
\text { and double layer switching coat and } \\
\text { pants }\end{array}$ \\
\hline
\end{tabular}

\section{Flash Protection Boundary [2]}

Pendekatan batas jarak dari bagian konduktor aktif dimana orang pada jarak tersebut dapat terpapar luka bakar tingkat dua jika ledakan busur api listrik terjadi. Jarak tersebut dapat diketahui apabila besar energi busur api listrik tersebut telah terhitung. Gambar 1. merupakan jarak batas dimana seseorang tanpa memakai alat pelindung yang memadai (Personal Protective Equipment/PPE) dapat terkena luka bakar tingkat dua yang sulit disembuhkan akibat ledakan busur api. Metode perhitungan jarak tersebut dijelaskan menurut persamaan IEEE 1584-2002 berikut.

$D_{B}=\left[4,184 \times C_{f} \times \operatorname{En} \times(t / 0,2)\left(610^{x} / E_{B}\right)\right]^{1 / x}$

\section{Dimana,}

$\mathrm{DB} \quad=$ batas jarak dari titik arcing $(\mathrm{mm})$

$\mathrm{Cf}_{\mathrm{f}} \quad$ faktor pengali

1,0 untuk tegangan di atas $1 \mathrm{kV}$

1,5 untuk tegangan di bawah $1 \mathrm{kV}$

En = incident energy normalized

$\mathrm{EB}_{\mathrm{B}}=$ incident energy in $\mathrm{J} / \mathrm{cm}^{2}$ at the boundary distance can be set at $5,0 \mathrm{~J} / \mathrm{cm}^{2}$ for bare skin (no hood)

$\mathrm{t} \quad=$ waktu (detik)

$\mathrm{X} \quad=$ eksponen jarak

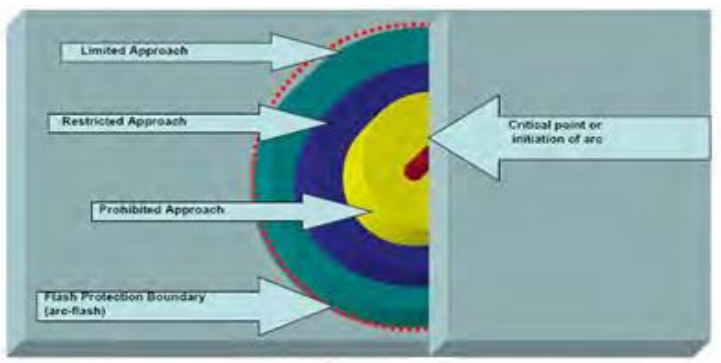

Gambar 1 Ilustrasi batas aman dari konduktor bertegangan.
Jaringan distribusi tenaga listrik yang digunakan di PT. Asahimas Flat Glass Tbk. Sidoarjo adalah sistem radial. Secara umum jaringan distribusi radial sering digunakan didalam industri karena memiliki beberapa keuntungan, yaitu:

- Lebih mudah dalam memperkirakan dan mengontrol aliran daya

- Mudah dalam perancangan sistem proteksi

- Biaya relatif lebih murah

- Arus gangguan yang mengalir biasanya lebih kecil

- Mudah dalam pengaturan tegangan

Untuk menentukan jenis distribusi jaringan biasanya ditentukan dengan kebutuhan pabrik itu sendiri. Pada umumnya biaya suatu sistem akan semakin meningkat seiring dengan keandalan suatu sistem yang didukung komponen dengan kualitas yang baik.

Sistem kelistrikan PT. Asahimas Flat Glass Tbk. Sidoarjo disuplai dari PLN dan sebagai back up menggunakan 7 buah generator. Berikut adalah kapasitas dari masing-masing suplai listrik di PT. Asahimas Flat Glass Tbk. Sidoarjo:

- Sumber dari gardu induk PLN 50 MVA

- Sumber dari gas engine generator $1250 \mathrm{kVA}(1$ buah)

- Sumber dari diesel engine generator 1650 $\operatorname{kVA}(6$ buah $)$

Pada PT. Asahimas Flat Glass Tbk. Sidoarjo sistem distribusi tegangan menengah yang digunakan adalah tegangan $20 \mathrm{kV}$ untuk suplai energi listrik. Sedangkan beban besar terkoneksi pada tegangan $3.15 \mathrm{kV}$.

Untuk merancang suatu sistem distribusi tenaga listrik yang baik dan memenuhi standar keandalan yanga ada maka diperlukan pertimbangan dan perhitungan yang matang. Secara umum sistem distribusi tenaga listrik di PT. Asahimas Flat Glass Tbk. Sidoarjo menggunakan sumber dari PLN, sedangkan untuk backup menggunakan diesel generator dan gas generator. Tegangan dari gardu induk PLN adalah $20 \mathrm{kV}$, kemudian diturunkan menggunakan trafo daya menjadi 3.15 $\mathrm{kV}$. Keluaran dari trafo dihubungkan ke bus $3.15 \mathrm{kV}$ yang akan didistribusikan kebeban menengah. Dari tegangan $3.15 \mathrm{kV}$ diturunkan lagi menjadi $0.4 \mathrm{kV}$ kemudian didistribusikan keseluruh beban. Distribusi ini didukung oleh trafo daya untuk menyuplai beban dengan rating tegangan dan daya tertentu.

Tabel 2.

Trafo Daya pada PT. Asahimas Flat Glass Tbk. Sidoarjo.

\begin{tabular}{|l|l|l|l|l|}
\hline No. & \multicolumn{1}{|c|}{ ID Trafo } & $\begin{array}{c}\text { Tegangan } \\
(\mathrm{kV})\end{array}$ & $\begin{array}{c}\text { Kapasitas } \\
(\mathrm{kVA})\end{array}$ & $\begin{array}{c}\text { Terhubung } \\
\text { pada Bus }\end{array}$ \\
\hline 1. & Trafo1 & $20 / 3.15$ & 9000 & Bus_PLN \\
\hline 2. & Trafo2 & $20 / 3.15$ & 9000 & Bus_PLN \\
\hline 3. & Trafo_1.1 & $3.15 / 0.4$ & 750 & Bus_1.1 \\
\hline 4. & Trafo_1.2 & $3.15 / 0.4$ & 500 & Bus_1.2 \\
\hline 5. & Trafo_1.3 & $3.15 / 0.4$ & 500 & Bus_1.3 \\
\hline 6. & Trafo_2.1 & $3.15 / 0.4$ & 1500 & Bus_2.1 \\
\hline 7. & Trafo_2.2 & $3.15 / 0.4$ & 1500 & Bus_2.2 \\
\hline 8. & Trafo_3.1 & $3.15 / 0.4$ & 300 & Bus_3.1 \\
\hline 9. & Trafo_3.5 & $3.15 / 0.4$ & 300 & Bus_3.5 \\
\hline 10. & Trafo_4.1 & $3.15 / 0.4$ & 750 & Bus_4.1 \\
\hline 11. & Trafo_5.2 & $3.15 / 0.4$ & 750 & Bus_5.2 \\
\hline
\end{tabular}




\begin{tabular}{|l|l|l|l|l|}
\hline 12. & Trafo_5.4 & $3.15 / 0.4$ & 500 & Bus_5.4 \\
\hline 13. & Trafo_5.5 & $3.15 / 0.4$ & 750 & Bus_5.5 \\
\hline 14. & Trafo_6.2 & $3.15 / 0.4$ & 500 & Bus_6.2 \\
\hline 15. & Trafo_6.5 & $3.15 / 0.4$ & 300 & Bus_6.5 \\
\hline 16. & Trafo_6.6 & $3.15 / 0.4$ & 300 & Bus_6.6 \\
\hline 17. & Trafo_7.1 & $3.15 / 0.4$ & 1500 & Bus_7.1 \\
\hline 18. & Trafo_7.2 & $3.15 / 0.4$ & 1500 & Bus_7.2 \\
\hline 19. & Trafo_8.1 & $3.15 / 0.4$ & 1500 & Bus_8.1 \\
\hline 20. & Trafo_8.2 & $3.15 / 0.4$ & 1500 & Bus_8.2 \\
\hline 21. & Trafo_8.3 & $3.15 / 0.4$ & 1500 & Bus_8.3 \\
\hline
\end{tabular}

\section{HASIL SIMULASI DAN ANALISA}

\section{A. Analisa Arc Flash Pada Tipikal 1}

Tabel 3 ini menunjukkan hasil energi arc flash pada sistem eksisting pada tipikal 1.

Tabel 3.

Hasil simulasi incident energy arc flash pada sistem eksisting tipikal 1

\begin{tabular}{|c|c|c|c|c|}
\hline ID & Ia (kA) & $\begin{array}{c}\text { Incident } \\
\text { Energy } \\
\left.\text { (cal/cm }^{2}\right)\end{array}$ & $\begin{array}{c}\text { Hazard Risk } \\
\text { Category }\end{array}$ & $\begin{array}{c}\text { Flash } \\
\text { Protection } \\
\text { Boundary }(\boldsymbol{m} \\
)\end{array}$ \\
\hline Bus TS1 & 9.409 & 31.576 & 4 & 26.34 \\
\hline $\begin{array}{c}\text { Bus } \\
\text { Substation\#2 }\end{array}$ & 9.324 & 5.955 & 2 & 4.74 \\
\hline Bus 2.1 & 27.35 & 31.002 & 4 & 5.54 \\
\hline
\end{tabular}

Tabel 4 ini menunjukkan hasil resetting nya.

Tabel 4.

Hasil simulasi incident energy arc flash pada sistem resetting tipikal 1

\begin{tabular}{|c|c|c|c|c|}
\hline ID & Ia $(\mathbf{k A})$ & $\begin{array}{c}\text { Incident } \\
\text { Energy } \\
\left(\mathrm{cal} / \mathrm{cm}^{2}\right)\end{array}$ & $\begin{array}{c}\text { Hazard Risk } \\
\text { Category }\end{array}$ & $\begin{array}{c}\text { Flash } \\
\text { Protection } \\
\text { Boundary(m } \\
\text { ) }\end{array}$ \\
\hline Bus TS1 & 9.409 & 10.049 & 3 & 8.7 \\
\hline $\begin{array}{c}\text { Bus } \\
\text { Substation\#2 }\end{array}$ & 9.324 & 5.742 & 2 & 4.56 \\
\hline Bus 2.1 & 27.35 & 16.167 & 3 & 3.56 \\
\hline
\end{tabular}

\section{- Bus_TS1}

Ibf $\quad=9.409 \mathrm{kA}$

FCT $=1.049 \mathrm{~s}$

$\mathrm{D} \quad=914.4 \mathrm{~mm}$

Berdasarkan data tersebut, maka :

\section{Mencari besar incident energy arc flash}

Ia

$$
\begin{aligned}
& =1.01 \times \mathrm{Ibf}^{0,983} \\
& =1.01 \times(9.409)^{0,983} \\
& =9.15 \mathrm{kA}
\end{aligned}
$$

En $\quad=\mathrm{Ia}^{1.081} \times 10^{(\mathrm{K} 1+\mathrm{K} 2+0.0011 \times \mathrm{G})}$

$=(9.15)^{1.081} \times 10^{(-0,555-0.113+0.0011 \times 102)}$

$=3.06 \mathrm{~J} / \mathrm{cm}^{2}$

$\mathrm{E} \quad=\operatorname{Cf} \times \operatorname{En} x\left(\frac{t}{0,2}\right)\left(\frac{610}{D}\right)^{x}$

$=1 \times 3.06\left(\frac{1.049}{0.2}\right)\left(\frac{610}{914.4}\right)^{0.973}$

$=10.75 \mathrm{cal} / \mathrm{cm}^{2}$

Mencari besar flash protection boundary

$\mathrm{D}_{\mathrm{B}}=\left[4,184 \cdot \mathrm{Cf} \cdot \mathrm{En} \cdot\left(\frac{t}{0,2}\right) \cdot\left(\frac{610^{x}}{E_{B}}\right)\right]^{\frac{1}{x}}$

$$
\begin{aligned}
& =\left[4,184 \cdot 1 \cdot 3.06 \cdot\left(\frac{1.049}{0,2}\right) \cdot\left(\frac{610^{0,973}}{5}\right)\right]^{\frac{1}{0,973}} \\
& =8746.7 \mathrm{~mm} \\
& =8.746 \mathrm{~m}
\end{aligned}
$$

- Bus_Substation\#2

Ibf $\quad=9.324 \mathrm{kA}$

FCT $=0.565 \mathrm{~s}$

$\mathrm{D} \quad=914.4 \mathrm{~mm}$

Berdasarkan data tersebut, maka :

\section{Mencari besar incident energy arc flash}

Ia $\quad=1.01 \times \mathrm{Ibf}^{0,983}$

$=1.01 \times(9.324)^{0,983}$

$=9.06 \mathrm{kA}$

En $\quad=\mathrm{Ia}^{1.081} \times 10^{(\mathrm{K} 1+\mathrm{K} 2+0.0011 \times \mathrm{G})}$

$=(9.06)^{1.081} \times 10^{(-0,555-0.113+0.0011 \times 102)}$

$=3.03 \mathrm{~J} / \mathrm{cm}^{2}$

$\mathrm{E} \quad=\operatorname{Cf} \times \operatorname{En} x\left(\frac{t}{0,2}\right)\left(\frac{610}{D}\right)^{x}$

$=1 \times 3.03\left(\frac{0.565}{0.2}\right)\left(\frac{610}{914.4}\right)^{0.973}$

$=5.73 \mathrm{cal} / \mathrm{cm}^{2}$

Mencari besar flash protection boundary

$\mathrm{D}_{\mathrm{B}}=\left[4,184 \cdot \mathrm{Cf} \cdot \mathrm{En} \cdot\left(\frac{t}{0,2}\right) \cdot\left(\frac{610^{x}}{E_{B}}\right)\right]^{\frac{1}{x}}$

$=\left[4,184 \cdot 1 \cdot 3 \cdot 03 \cdot\left(\frac{0.565}{0,2}\right) \cdot\left(\frac{610^{0,973}}{5}\right)\right]^{\frac{1}{0,973}}$

$=4568.4 \mathrm{~mm}$

$=4.568 \mathrm{~m}$

- Bus_2.1

$\begin{array}{ll}\text { Ibf } & =27.35 \mathrm{kA} \\ \mathrm{Ia} & =12.34 \mathrm{kA} \\ \mathrm{FCT} & =0.729 \mathrm{~s} \\ \mathrm{D} & =609.6 \mathrm{~mm}\end{array}$

Berdasarkan data tersebut, maka :

\section{Mencari besar incident energy arc flash}

En

$$
\begin{aligned}
& =\mathrm{Ia}^{1.081} \times 10^{(\mathrm{K} 1+\mathrm{K} 2+0.0011 \times \mathrm{G})} \\
& =(12.34)^{1.081} \times 10^{(-0,555-0.113+0.0011 \times 32)} \\
& =3.02 \mathrm{~J} / \mathrm{cm}^{2} \\
& =\mathrm{Cf} \times \mathrm{En} \times\left(\frac{t}{0,2}\right)\left(\frac{610}{D}\right)^{x} \\
& =1.5 \times 3.02\left(\frac{0.729}{0.2}\right)\left(\frac{610}{609.6}\right)^{1.473} \\
& =16.15 \mathrm{cal} / \mathrm{cm}^{2}
\end{aligned}
$$$$
\mathrm{E} \quad=\operatorname{Cf} \times \operatorname{En} x\left(\frac{t}{0,2}\right)\left(\frac{610}{D}\right)^{x}
$$

Mencari besar flash protection boundary

$\mathrm{D}_{\mathrm{B}}=\left[4,184 \cdot \mathrm{Cf} \cdot 3.02 \cdot\left(\frac{t}{0,2}\right) \cdot\left(\frac{610^{x}}{E_{B}}\right)\right]^{\frac{1}{x}}$ 


$$
\begin{aligned}
& =\left[4,184 \cdot 1 \cdot 5 \cdot 3.02 \cdot\left(\frac{0.729}{0,2}\right) \cdot\left(\frac{610^{1.473}}{5}\right)\right]^{\frac{1}{1.473}} \\
& =3546.8 \mathrm{~mm} \\
& =3.546 \mathrm{~m}
\end{aligned}
$$

B. Analisa Arc Flash Pada Tipikal 2.

Tabel 5

Hasil simulasi incident energy arc flash pada sistem eksisting tipikal 2.

\begin{tabular}{|c|c|c|c|c|}
\hline ID & Ia (kA) & $\begin{array}{c}\text { Incident } \\
\text { Energy } \\
\left(\text { cal/cm }^{2}\right)\end{array}$ & $\begin{array}{c}\text { Hazard Risk } \\
\text { Category }\end{array}$ & $\begin{array}{c}\text { Flash } \\
\text { Protection } \\
\text { Boundary }(\boldsymbol{m} \\
)\end{array}$ \\
\hline Bus TS2 & 10.46 & 30.387 & 4 & 25.32 \\
\hline $\begin{array}{c}\text { Bus Station } \\
\text { Service }\end{array}$ & 10.31 & 4.696 & 2 & 3.71 \\
\hline Bus 6.2 & 11.79 & 9.596 & 3 & 2.49 \\
\hline
\end{tabular}

Tabel 6

Hasil simulasi incident energy arc flash pada sistem reseting tipikal 2.

\begin{tabular}{|c|c|c|c|c|}
\hline ID & Ia (kA) & $\begin{array}{c}\text { Incident } \\
\text { Energy } \\
\left(\text { cal/.cm }^{2}\right)\end{array}$ & $\begin{array}{c}\text { Hazard Risk } \\
\text { Category }\end{array}$ & $\begin{array}{c}\text { Flash } \\
\text { Protection } \\
\text { Boundary }(\boldsymbol{m} \\
)\end{array}$ \\
\hline Bus TS2 & 10.46 & 16.8 & 3 & 13.78 \\
\hline $\begin{array}{c}\text { Bus Station } \\
\text { Service }\end{array}$ & 10.31 & 4.053 & 2 & 3.19 \\
\hline Bus 6.2 & 11.79 & 5.123 & 2 & 1.63 \\
\hline
\end{tabular}

\section{- Bus_TS2}

Ibf $\quad=10.46 \mathrm{kA}$

FCT $=1.465 \mathrm{~s}$

$\mathrm{D} \quad=914.4 \mathrm{~mm}$

Berdasarkan data tersebut, maka :

\section{Mencari besar incident energy arc flash}

Ia $\quad=1.01 \times \mathrm{Ibf}^{0,983}$

$=1.01 \times(10.46)^{0,983}$

$=10.15 \mathrm{kA}$

En $\quad=\mathrm{Ia}^{1.081} \times 10^{(\mathrm{K} 1+\mathrm{K} 2+0.0011 \times \mathrm{G})}$

$=(10.15)^{1.081} \times 10^{(-0,555-0.113+0.0011 \times 102)}$

$=3.4 \mathrm{~J} / \mathrm{cm}^{2}$

$\mathrm{E} \quad=\operatorname{Cf} \times \operatorname{En} x\left(\frac{t}{0,2}\right)\left(\frac{610}{D}\right)^{x}$

$=1 \times 3.4\left(\frac{1.465}{0.2}\right)\left(\frac{610}{914.4}\right)^{0.973}$

$=16.8 \mathrm{cal} / \mathrm{cm}^{2}$

Mencari besar flash protection boundary

$\mathrm{D}_{\mathrm{B}}=\left[4,184 \cdot \mathrm{Cf} \cdot \mathrm{En} \cdot\left(\frac{t}{0,2}\right) \cdot\left(\frac{610^{x}}{E_{B}}\right)\right]^{\frac{1}{x}}$

$=\left[4,184 \cdot 1 \cdot 3 \cdot 4 \cdot\left(\frac{1 \cdot 465}{0,2}\right) \cdot\left(\frac{610^{0,973}}{5}\right)\right]^{\frac{1}{0,973}}$

$=13778 \mathrm{~mm}$

$=13.778 \mathrm{~m}$

\footnotetext{
- Bus_Station_Service

Ibf $\quad=10.31 \mathrm{kA}$

FCT $\quad=0.358 \mathrm{~s}$
}

$\mathrm{D} \quad=914.4 \mathrm{~mm}$

Berdasarkan data tersebut, maka :

\section{Mencari besar incident energy arc flash}

Ia $\quad=1.01 \times$ Ibf $^{0,983}$

$$
=1.01 \times(10.31)^{0,983}
$$

$$
=10 \mathrm{kA}
$$

En $\quad=\mathrm{Ia}^{1.081} \times 10^{(\mathrm{K} 1+\mathrm{K} 2+0.0011 \times \mathrm{G})}$

$=(10)^{1.081} \times 10^{(-0,555-0.113+0.0011 \times 102)}$

$=3.4 \mathrm{~J} / \mathrm{cm}^{2}$

$\mathrm{E} \quad=\operatorname{Cf} x \operatorname{En} x\left(\frac{t}{0,2}\right)\left(\frac{610}{D}\right)^{x}$

$=1 \times 3.4\left(\frac{0.354}{0.2}\right)\left(\frac{610}{914.4}\right)^{0.973}$

$=4.05 \mathrm{cal} / \mathrm{cm}^{2}$

Mencari besar flash protection boundary

$$
\begin{aligned}
\mathrm{D}_{\mathrm{B}} & =\left[4,184 \cdot \mathrm{Cf} \cdot \mathrm{En} \cdot\left(\frac{t}{0,2}\right) \cdot\left(\frac{610^{x}}{E_{B}}\right)\right]^{\frac{1}{x}} \\
& =\left[4,184 \cdot 1 \cdot 3.4 \cdot\left(\frac{0.354}{0,2}\right) \cdot\left(\frac{610^{0,973}}{5}\right)\right]^{\frac{1}{0,973}} \\
& =3193.8 \mathrm{~mm} \\
& =3.193 \mathrm{~m}
\end{aligned}
$$

- Bus_6.2

$\begin{array}{ll}\text { Ibf } & =11.79 \mathrm{kA} \\ \mathrm{Ia} & =5.4 \mathrm{kA} \\ \mathrm{FCT} & =0.473 \mathrm{~s} \\ \mathrm{D} & =609.6 \mathrm{~mm}\end{array}$

Berdasarkan data tersebut, maka :

Mencari besar incident energy arc flash

En $\quad=\mathrm{Ia}^{1.081} \times 10^{(\mathrm{K} 1+\mathrm{K} 2+0.0011 \times \mathrm{G})}$

$=(5.4)^{1.081} \times 10^{(-0,555-0.113+0.0011 \times 32)}$

$=1.44 \mathrm{~J} / \mathrm{cm}^{2}$

$\mathrm{E} \quad=\operatorname{Cf} \times \operatorname{En} \times\left(\frac{t}{0,2}\right)\left(\frac{610}{D}\right)^{x}$

$=1.5 \times 1.44\left(\frac{0.473}{0.2}\right)\left(\frac{610}{609.6}\right)^{1.473}$

$=5.12 \mathrm{cal} / \mathrm{cm}^{2}$

Mencari besar flash protection boundary

$\mathrm{D}_{\mathrm{B}} \quad=\left[4,184 \cdot \mathrm{Cf} \cdot \mathrm{En} \cdot\left(\frac{t}{0,2}\right) \cdot\left(\frac{610^{x}}{E_{B}}\right)\right]^{\frac{1}{x}}$

$=\left[4,184 \cdot 1.5 \cdot 1.44 \cdot\left(\frac{0.473}{0,2}\right) \cdot\left(\frac{610^{1.473}}{5}\right)\right]^{\frac{1}{1.473}}$

$=1632.5 \mathrm{~mm}$

$=1.632 \mathrm{~m}$

C. Analisa Arc Flash pada Tipikal 3

Tabel 7

Hasil simulasi incident energy arc flash pada sistem eksisting tipikal 3. 


\begin{tabular}{|c|c|c|c|c|}
\hline ID & Ia (kA) & $\begin{array}{c}\text { Incident } \\
\text { Energy } \\
\left(\text { cal/.cm }^{2}\right)\end{array}$ & $\begin{array}{c}\text { Hazard Risk } \\
\text { Category }\end{array}$ & $\begin{array}{c}\text { Flash } \\
\text { Protection } \\
\text { Boundary }(\boldsymbol{m}\end{array}$ \\
\hline Bus TS2 & 10.46 & 30.387 & 4 & 25.32 \\
\hline $\begin{array}{c}\text { Bus Bath } \\
\text { Heater }\end{array}$ & 10.38 & 9.302 & 3 & 7.5 \\
\hline Bus 8.1 & 28.34 & 30.513 & 4 & 5.48 \\
\hline
\end{tabular}

Tabel 8

Hasil simulasi incident energy arc flash pada sistem reseting tipikal 3.

\begin{tabular}{|c|c|c|c|c|}
\hline ID & Ia $(\mathbf{k A})$ & $\begin{array}{c}\text { Incident } \\
\text { Energy } \\
\left(\mathrm{cal} / \mathrm{cm}^{2}\right)\end{array}$ & $\begin{array}{c}\text { Hazard Risk } \\
\text { Category }\end{array}$ & $\begin{array}{c}\text { Flash } \\
\text { Protection } \\
\text { Boundary }(m \\
\text { ) }\end{array}$ \\
\hline Bus TS2 & 10.46 & 16.8 & 3 & 13.78 \\
\hline $\begin{array}{c}\text { Bus Bath } \\
\text { Heater }\end{array}$ & 10.38 & 7.23 & 2 & 5.79 \\
\hline $\begin{array}{l}\text { Bus } 8.1 \\
\end{array}$ & 28.34 & 15.94 & 3 & 3.5 \\
\hline
\end{tabular}

\section{- Bus_Bath_Heater \\ Ibf $\quad=10.38 \mathrm{kA}$ \\ $\mathrm{FCT}=0.636 \mathrm{~s}$ \\ $\mathrm{D} \quad=914.4 \mathrm{~mm}$}

Berdasarkan data tersebut, maka :

\section{Mencari besar incident energy arc flash}

$$
\begin{aligned}
\text { Ia } & =1.01 \times \mathrm{Ibf}^{0,983} \\
& =1.01 \times(10.38)^{0,983} \\
& =10.07 \mathrm{kA} \\
\mathrm{En} & =\mathrm{Ia}^{1.081} \times 10^{(\mathrm{K} 1+\mathrm{K} 2+0.0011 \times \mathrm{G})} \\
& =(10.07)^{1.081} \times 10^{(-0,555-0.113+0.0011 \times 102)} \\
& =3.37 \mathrm{~J} / \mathrm{cm}^{2} \\
\mathrm{E} & =\mathrm{Cf} \times \mathrm{En} \times\left(\frac{t}{0,2}\right)\left(\frac{610}{D}\right)^{x} \\
& =1 \times 3.37\left(\frac{0.636}{0.2}\right)\left(\frac{610}{914.4}\right)^{0.973} \\
& =7.22 \mathrm{cal} / \mathrm{cm}^{2}
\end{aligned}
$$

Mencari besar flash protection boundary

$$
\begin{aligned}
\mathrm{D}_{\mathrm{B}} \quad & =\left[4,184 \cdot \operatorname{Cf} \cdot \operatorname{En} \cdot\left(\frac{t}{0,2}\right) \cdot\left(\frac{610^{x}}{E_{B}}\right)\right]^{\frac{1}{x}} \\
& =\left[4,184 \cdot 1 \cdot 3.37 \cdot\left(\frac{0.636}{0,2}\right) \cdot\left(\frac{610^{0,973}}{5}\right)\right]^{\frac{1}{0,973}} \\
& =5796.4 \mathrm{~mm} \\
& =5.796 \mathrm{~m}
\end{aligned}
$$

\section{- Bus_8.1}

$$
\begin{array}{ll}
\mathrm{Ibf} & =28.34 \mathrm{kA} \\
\mathrm{Ia} & =12.68 \mathrm{kA} \\
\mathrm{FCT} & =0.697 \mathrm{~s} \\
\mathrm{D} & =609.6 \mathrm{~mm}
\end{array}
$$

Berdasarkan data tersebut, maka :

\section{Mencari besar incident energy arc flash}

En $\quad=\mathrm{Ia}^{1.081} \times 10^{(\mathrm{K} 1+\mathrm{K} 2+0.0011 \times \mathrm{G})}$

$$
=(12.688)^{1.081} \times 10^{(-0,555-0.113+0.0011 \times 32)}
$$$$
=3.1 \mathrm{~J} / \mathrm{cm}^{2}
$$

$$
\begin{aligned}
\mathrm{E} & =\operatorname{Cf} \times \operatorname{En} \times\left(\frac{t}{0,2}\right)\left(\frac{610}{D}\right)^{x} \\
& =1.5 \times 3.1\left(\frac{0.697}{0.2}\right)\left(\frac{610}{609.6}\right)^{1.473} \\
& =15.9 \mathrm{cal} / \mathrm{cm}^{2}
\end{aligned}
$$

Mencari besar flash protection boundary

$$
\begin{aligned}
\mathrm{D}_{\mathrm{B}} & =\left[4,184 . \mathrm{Cf} \cdot \mathrm{En} \cdot\left(\frac{t}{0,2}\right) \cdot\left(\frac{610^{x}}{E_{B}}\right)\right]^{\frac{1}{x}} \\
& =\left[4,184 \cdot 1.5 \cdot 3 \cdot 1 \cdot\left(\frac{0.673}{0,2}\right) \cdot\left(\frac{610^{1.473}}{5}\right)\right]^{\frac{1}{1.473}} \\
& =3527.9 \mathrm{~mm} \\
& =3.527 \mathrm{~m}
\end{aligned}
$$

D. Perbandingan Nilai Flash Protection Boundary (FPB) Kondisi Existing dan Resetting

Flash Protection Boundary merupakan jarak aman perkerja dari titik terjadinya busur api, atau jarak dari titik busur api yang dapat menghasilkan energi $1,2 \mathrm{cal} / \mathrm{cm}^{2}$. Dalam jarak batasan ini, seseorang masih diperbolehkan untuk tidak menggunakan alat perlindungan diri yang sesuai, tetapi ketika melewati batasan ini, seseorang diwajibkan untuk memakain alat perlindungan diri yang sesuai. Seberapa jauh jarak FPB ini tergantung dari besar energi yang dihasilkan. Semakin besar energinya maka semakin jauh pula jarak amannya, demikian sebaliknya. Nilai FPB akan dibandingkan ketika kondisi existing dan resetting.

Tabel 4.9

Data Perbandingan FPB Kondisi Existing dan Resetting

\begin{tabular}{|c|c|c|}
\hline Bus ID & $\begin{array}{c}\text { FPB Eksisting } \\
\text { (meter) }\end{array}$ & $\begin{array}{c}\text { FPB Resetting } \\
\text { (meter) }\end{array}$ \\
\hline Bus_2.1 & 5.54 & 3.56 \\
\hline Bus_Substation\#2 & 4.74 & 4.56 \\
\hline Bus_TS1 & 26.34 & 8.7 \\
\hline Bus_6.2 & 2.49 & 1.63 \\
\hline Bus_Station_Service & 3.71 & 3.19 \\
\hline Bus_TS2 & 25.32 & 13.78 \\
\hline Bus_8.1 & 5.48 & 3.5 \\
\hline Bus_Bath_Heater & 7.5 & 5.79 \\
\hline
\end{tabular}

E. Perbandingan Incident Energy Arc Flash Kondisi Resetting Antara Simulasi dan Perhitungan

Perbandingan antara perhitungan manual dan hasil simulasi resetting perlu dilakukan agar diketahui kesalahan dari analisa arc flash. Pada tabel dibawah ini akan ditunjukkan perbandingannya secara persentase.

Tabel 4.10

Perbandingan incident energy arc flash pada tipikal

\begin{tabular}{|l|c|c|c|}
\hline ID Bus & Simulasi & Perhitungan & Error (\%) \\
\hline Bus TS1 & 10.764 & 10.75 & 0.13 \\
\hline $\begin{array}{l}\text { Bus } \\
\text { Substation\#2 }\end{array}$ & 5.742 & 5.73 & 0.2 \\
\hline Bus 2.1 & 16.167 & 16.15 & 0.1 \\
\hline
\end{tabular}

Tabel 4.11

Perbandingan incident energy arc flash pada tipikal 2

\begin{tabular}{l|c|c|c} 
ID Bus & Simulasi & Perhitungan & Error (\%)
\end{tabular}




\begin{tabular}{|c|c|c|c|}
\hline $\begin{array}{c}\text { Bus Station } \\
\text { Service }\end{array}$ & 4.053 & 4.05 & 0.07 \\
\hline Bus 6.2 & 5.123 & 5.12 & 005 \\
\hline
\end{tabular}

Tabel 4.12

Perbandingan incident energy arc flash pada tipikal 3

\begin{tabular}{|c|c|c|c|}
\hline ID Bus & Simulasi & Perhitungan & Error (\%) \\
\hline Bus TS2 & 16.8 & 16.8 & 0.0 \\
\hline $\begin{array}{c}\text { Bus Bath } \\
\text { Heater }\end{array}$ & 7.23 & 7.22 & 0.13 \\
\hline Bus 8.1 & 15.94 & 15.9 & 0.2 \\
\hline
\end{tabular}

F. Personal Protective Equipment (PPE) yang Harus Digunakan

Personal Protective Equipment (PPE) merupakan alat perlindungan diri yang harus digunakan ketika melakukan suatu pekerjaan didaerah yang beresiko terkena busur api.

Penting untuk menganalisa dan mengetahui besar energi busur api yang ada agar mengetahui jenis PPE yang tepat yang harus digunakan supaya dapat menurunkan resiko terkena dampak dari busur api bagi para pekerja terkait.

Tabel 4.13

Jenis PPE Berdasarkan Kategori Bahaya Busur Api Setelah Resetting

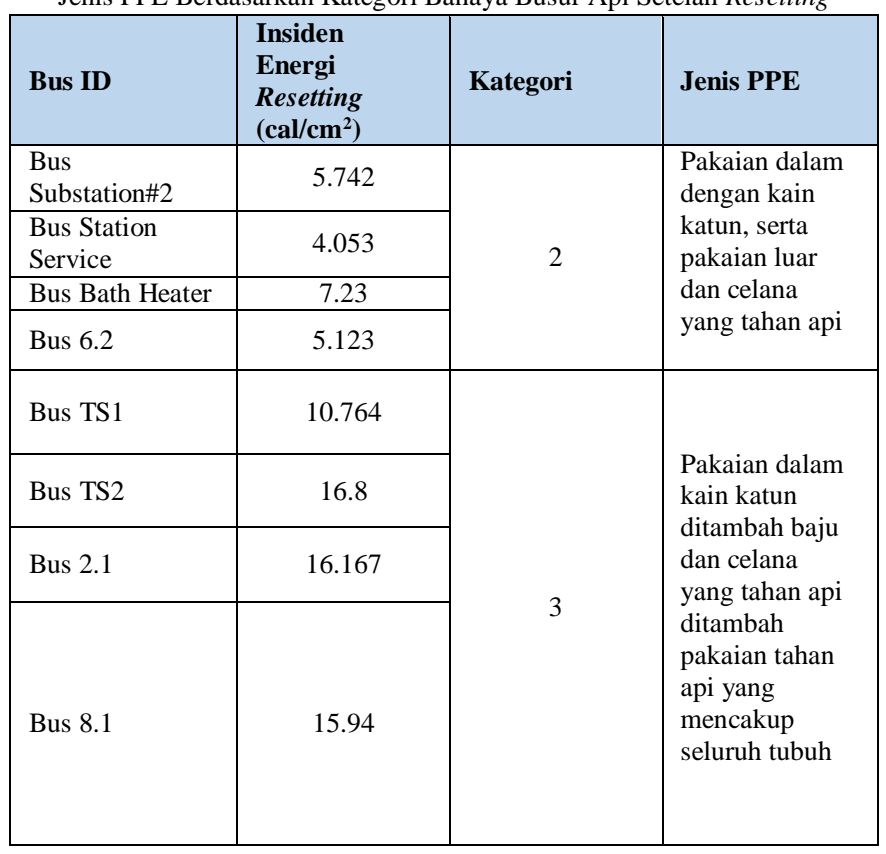

\section{KESIMPULAN}

1. Setelah dilakukan Resetting dengan menyesuaikan waktu trip menyebabkan insiden energi yang ada semakin berkurang.

2. Untuk hasil yang didapat pada tugas akhir ini adalah pada tipikal 1 nilai insiden energi tertinggi $31.576 \mathrm{cal} / \mathrm{cm}^{2}$ turun menjadi $10.764 \mathrm{cal} / \mathrm{cm}^{2}$, pada tipikal 2 nilai insiden energi tertinggi $30.387 \mathrm{cal} / \mathrm{cm}^{2}$ turun menjadi $16.8 \mathrm{cal} / \mathrm{cm}^{2}$, pada tipikal 3 nilai insiden energi nya mengalami penurunan yaitu dari $30.513 \mathrm{cal} / \mathrm{cm}^{2}$ menjadi $15.94 \mathrm{cal} / \mathrm{cm}^{2}$.

3. Dengan mengetahui klasifikasi katagori arc flash pada setiap bus kita bisa menggunakan APD yang sesuai pada saat melakukan pekerjaan di area tersebut.
4. Pengklasifikasian kategori dan alat perlindungan diri yang tepat dapat memberikan rasa aman dan nyaman bagi para pekerja sehingga dapat bekerja secara optimal. Selain itu juga untuk menghindari jatuhnya korban jiwa akibat ledakan busur api.

\section{DAFTAR PUSTAKA}

[1] Hurst, Randolph W., "Electrical Safety and Arc Flash Handbook, volume 5", (C) National Safety, Inc., 2009.

[2] Pfeiffer, John C., "Arc Flash Article", Pfeiffer Engineering Co., Inc.,2008.

[3] IEEE Std. 1584-2002., "IEEE Guide for Performing ArcFlash Hazard Calculation", by the Institute of Electrical and Electronics Engineers, Inc., 2002.

[4] Chet Davis, P.E., Conrad St. Pierre, Dave Castor, P.E., Robert Luo, Ph.D., Satish Shrestha, "Practical Solution Guide to Arc Flash Hazard”.

[5] NFPA 70E., "Electrical Safety Requirements for Employee Workplaces 2003 Edition”, NFPA 70E-2003. 